\title{
Refractory WHO Grade II Glioma
}

National Cancer Institute

\section{Source}

National Cancer Institute. Refractory WHO Grade II Glioma. NCI Thesaurus. Code C158104.

A WHO grade II glioma that is resistant to treatment. 